\title{
Review: inhaled corticosteroids slow the progression of airflow limitation in COPD
}

Sutherland ER, Allmers H, Ayas NT, et al. Inhaled corticosteroids reduce the progression of airflow limitation in chronic obstructive pulmonary disease: a meta-analysis. Thorax 2003;58:937-41.

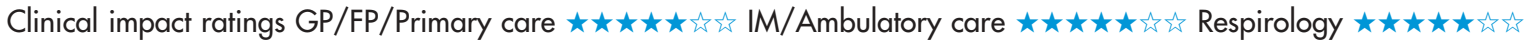

In patients with chronic obstructive pulmonary disease (COPD), do inhaled corticosteroids (ICSs) reduce the progression of airflow limitation?

\section{METHODS}

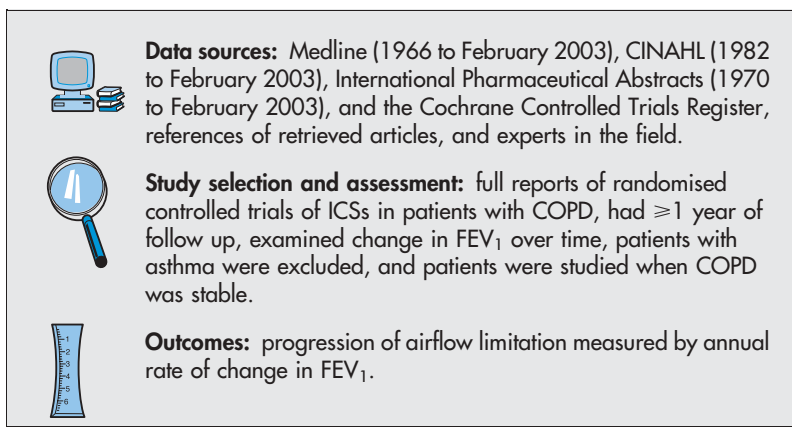

\section{MAIN RESULTS}

8 trials $(\mathrm{n}=3715)$ were included. All trials were $\geqslant 2$ years in duration (range $24-40 \mathrm{mo}$ ). The ICSs studied were fluticasone, triamcinolone, budesonide, and beclomethasone. ICSs reduced the rate of decline in $\mathrm{FEV}_{1}$ more than did placebo (table). Meta-analysis with trials of high dose ICS regimens ( 4 trials, 2416 patients) also favoured ICSs (table).

\section{CONCLUSION}

In patients with chronic obstructive pulmonary disease, inhaled corticosteroids reduce the progression of airflow limitation.

Abstract and commentary also appear in ACP Journal Club.

Inhaled corticosteroids $v$ placebo for chronic obstructive pulmonary disease at 24-40 months ${ }^{*}$

\begin{tabular}{ll}
\hline Trials & $\begin{array}{l}\text { Annual reduction in } \mathrm{FEV}_{1} \text { decline } \\
(95 \% \mathrm{Cl})\end{array}$ \\
\hline $\begin{array}{l}\text { All trials }(8 \text { trials, } \mathrm{n}=3715) \\
\text { Trials with high-dose regimens }\end{array}$ & $7.7 \mathrm{ml} / \mathrm{y}(1.3$ to 14.2$)$ \\
(4 trials, $\mathrm{n}=2416)$ & $9.9 \mathrm{ml} / \mathrm{y}(2.3$ to 17.5$)$ \\
\hline
\end{tabular}

*Values are means. $\mathrm{Cl}$ defined in glossary. A random effects model was used.

\section{Commentary}

OPD is largely a disease of vulnerable smokers in whom the normal age related decline in lung function is accelerated from a mean of $30 \mathrm{ml} / \mathrm{y}$ to $60 \mathrm{ml} / \mathrm{y}$. Unlike asthma, the airflow obstruction and airway inflammation of COPD respond poorly to corticosteroids. The review of randomised controlled trials by Sutherland et al shows a statistically significant reduction in the annual rate of decline in $\mathrm{FEV}_{1}$ of $7.7 \mathrm{ml} / \mathrm{y}$ with higher dose regimens, and patients with more severe disease obtained greater benefit. Although the absolute reduction was small, it represents a reduction in the rate of decline of about $15 \%$ in smokers compared with a reduction of about $50 \%$ as a result of smoking cessation. ${ }^{1}$

COPD is now our fourth most common cause of death, and no drugs apart from oxygen alter the natural history of the disease. But should any intervention that slows the inexorable decline in lung function be welcomed? Arguably, the small advantage in terms of reduced decline in $\mathrm{FEV}_{1}$ is of little clinical relevance. Furthermore, widespread introduction of high dose ICSs for all patients with COPD would be expensive given the prevalence of the disease and its long term course. In my opinion, we should put the resources into vigorous smoking prevention and cessation programmes that are more effective in terms of preserving lung function (as well as preventing cancer and heart disease). Pressure to prescribe these drugs for many patients with essentially irreversible airflow obstruction can be resisted but emphasises the importance of distinguishing asthma from COPD.

The discrepancy between the results of the systematic reviews of Highland et af and Sutherland et al will also fuel current anxieties about the validity of meta-analysis, especially as nearly identical trial data were incorporated in these 2 reviews. In fact, the rate of decline in $\mathrm{FEV}_{1}$ in both analyses was very similar $(5 \mathrm{ml} / \mathrm{y}$ and $7.7 \mathrm{ml} / \mathrm{y}$, respectively) but the former failed to reach statistical significance. The differences emphasise how apparently uncontroversial assumptions made during data extraction can have substantial effects on the primary outcome and might lead to very different recommendations in "evidence-based" clinical guidelines. Readers of meta-analyses need to be vigilant as to the absolute size of the effects of any intervention and aware that pooling trial data can be a hazardous activity.

Michael Greenstone, MD, FRCP Castle Hill Hospital Cottingham, UK

1 Anthonisen NR, Connett JE, Murray RP. Smoking and lung function of Lung Health Study participants after 11 years. Am J Respir Crit Care Med 2002;166:675-9.

2 Highland KB, Strange C, Heffner JE. Long-term effects of inhaled corticosteroids on FEVI in patients with chronic obstructive pulmonary disease. A meta-analysis. Ann Intern Med 2003;138:969-73.

For correspondence: Dr E R Sutherland, National Jewish Medical and Research Center and the University of Colorado Health Sciences Center, Denver, CO, USA. sutherlande@nic.org

Sources of funding: National Institutes of Health and Wellcome Trust. 